\title{
A naturalização da miséria contemporânea: análise discursiva crítica de uma circular de condomínio
}

Viviane de Melo Resende

Universidade de Brasília - UnB

RESUMO: Neste trabalho, parto do referencial teórico e metodológico da Análise de Discurso Crítica para analisar o relatório de uma reunião, apresentado como circular aos/às condôminos/as de um prédio de classe média da Asa Sul de Brasília. O tema da circular é uma reunião, realizada entre o síndico do prédio, comerciantes locais e autoridades do Governo do Distrito Federal, acerca de um grupo de "moradores de rua" que se havia estabelecido nas proximidades do edifício residencial e de estabelecimentos do comércio local. $\mathrm{O}$ texto foi analisado discursivamente, tendo como categorias analíticas estrutura genérica, modalidade, intertextualidade, pressuposição e avaliação. Discuto a naturalização da miséria em sociedades contemporâneas a partir da internalização de discursos hegemônicos os quais operam um apagamento de direitos sociais básicos.

PALAVRAS-CHAVE: Análise de Discurso Crítica; situação de rua; apartação.

ABSTRACT: Based upon Critical Discourse Analysis, this study analyses a report of a meeting, distributed as a circular to residents of a middle-class apartment building in Brasília. The circular is the outcome of a meeting held between the apartment building's representative, local businesspeople and Federal District Government authorities concerning "street dwellers" in the surrounding of the apartment building and local business establishments. The circular is considered discursively in terms of its generic structure, modality, intertextuality, presupposition and evaluation. The analysis seeks to discuss the naturalization of misery in contemporary societies through the internalization of hegemonic discourses that serve to erase basic social rights. The study argues that this is due to the repetition of these discourses in different institutional environments and in various text types.

KEY-WORDS: Critical Discourse Analysis; street dwellers; social apartheid.

\section{Introdução}

Neste trabalho, parto do referencial teórico e metodológico da Análise de Discurso Crítica (CHOULIARAKI; FAIRCLOUGH, 1999; FAIRCLOUGH, 2003) para analisar o relatório de uma reunião, apresentado como circular aos/ às condôminos/as de um prédio de classe média da Asa Sul de Brasília, Distrito Federal, Brasil. 
O tema da circular é uma reunião, realizada entre o síndico do prédio, comerciantes locais e autoridades do Governo do Distrito Federal, acerca de um grupo de "moradores de rua" que havia se estabelecido nas proximidades do edifício residencial e de estabelecimentos do comércio local. A análise discursiva mostra que o texto opera, por um lado, uma dissimulação do problema da situação de rua e, por outro, o expurgo de pessoas nessas condiçóes (THOMPSON, 1995), por meio da legitimação da apartação na sociedade brasiliense (BUARQUE, 2003). Meu objetivo com essa análise é discutir a naturalização da miséria em sociedades contemporâneas a partir da internalização de discursos hegemônicos os quais operam um apagamento de direitos sociais básicos. Argumento que isso se dá em decorrência da repetibilidade desses discursos em diferentes ambientes institucionais e em variados tipos de texto.

$\mathrm{O}$ artigo está dividido em quatro seções. Na primeira, abordo a Análise de Discurso Crítica como ferramenta para a análise de textos envolvendo situaçóes de precariedade social. Em seguida, na segunda seção, discuto a precariedade social e a situação de rua como questóes sociais. Na terceira seção, contextualizo o problema em foco na circular de condomínio a ser analisada. Por fim, na quarta seção, apresento as categorias analíticas que serão utilizadas na análise discursiva do texto e procedo à análise, a fim de chegar a conclusóes sobre a matriz social do texto e seus efeitos ideológicos.

\section{Análise de Discurso Crítica como ferramenta para análise de problemas sociais}

A acomodação de sociedades hodiernas à pobreza extrema e a conseqüente invisibilidade de pessoas em situação de rua são problemas parcialmente discursivos, atrelados à naturalização de discursos dominantes acerca da precarização social e à dissimulação de questôes sociais graves. Sendo assim, são objetos analíticos para a Análise de Discurso Crítica (ADC), dada sua agenda de engajamento como prática teórica crítica para a mudança social. A ADC configura-se um corpo teórico da linguagem na modernidade que, alimentada nas Ciências Sociais, apresenta um foco específico nos modos como a linguagem figura na vida social e um conjunto de métodos para a análise lingüística de dados empíricos, entendendo o texto - em sentido amplo: escrito, oral, visual - como unidade mínima de análise (WODAK, 2003).

Trata-se de um corpo teórico e um conjunto de métodos porque não há unidade de abordagem sob o rótulo $\mathrm{ADC}$, ao contrário, há uma variedade de propostas baseadas em diferentes relações transdisciplinares entre a 
Lingüística e as Ciências Sociais (por exemplo, van Dijk propóe uma articulação voltada para a Psicologia Social e Wodak sugere uma articulação com a História). Neste trabalho, o foco de interesse é a abordagem de ADC desenvolvida por Norman Fairclough, que defende a articulação entre a Lingüística e a Ciência Social Crítica. Não se trata de limitar a ADC ao trabalho de Fairclough; trata-se antes de, reconhecendo a heterogeneidade, reconhecer também a necessidade de um foco específico para o desenvolvimento de pesquisas.

Nessa versão de $\mathrm{ADC}$, os trabalhos de pesquisa partem da identificação de problemas sociais parcialmente discursivos que possam ser investigados por meio da análise situada de textos (CHOULIARAKI; FAIRCLOUGH, 1999). A análise lingüística, então, é utilizada como ferramenta para a crítica social, e o uso de categorias propriamente lingüísticas se justifica à medida que tais categorias analíticas evidenciem questôes de caráter social, na criação/ manutenção ou na subversão/transformação de situações de dominação. Por isso essa proposta afina-se com o trabalho ora apresentado. Não tenho nenhum pudor em advertir: sou uma pesquisadora engajada.

A vantagem de uma análise de discurso textualmente orientada é oferecer subsídios para uma análise social fundamentada em dados lingüísticos que sustentem a crítica explanatória. Por meio de análises discursivas críticas, é possível mapear conexões entre escolhas lingüísticas de atores sociais ou grupos e os contextos sociais mais amplos nos quais os textos analisados são formulados. Assim, é gerado conhecimento acerca da internalização de discursos na construção de identidades e na constituição de relaçôes sociais, acerca da utilização de estruturas lingüísticas com propósitos políticos, acerca da relação entre os momentos discursivos e não discursivos de práticas sociais específicas (sobre o discurso como momento de práticas sociais, ver CHOULIARAKI; FAIRCLOUGH, 1999).

Assim, a ADC provê meios para se investigarem os modos como a linguagem figura na vida social, possibilitando o desvelamento da universalização de discursos particulares e da vinculação de textos particulares a ideologias, entendidas como construções simbólicas a serviço da manutenção de estruturas de dominação (THOMPSON, 1995). Por isso a ADC é considerada uma ferramenta poderosa para pesquisas compromissadas com objetivos éticos e políticos no tangente à precariedade social, uma vez que um dos objetivos de pesquisas dessa natureza é apontar como certos discursos naturalizam a injustiça social e dissimulam problemas sociais para mostrar como isso se atualiza em 
instanciações discursivas concretas (para uma formulação mais detida acerca da ADC, ver RESENDE; RAMALHO, 2006).

\section{A precariedade social e a situação de rua}

Um problema imediato para quem estuda a situação política e socialmente constrangedora de haver pessoas que, no contexto da modernidade, são deixadas à margem dessa mesma modernidade e são submetidas à vida nas ruas é o da denominação que se deve dar a essa situação. Considerando que diferentes discursos 'lexicalizam' o mundo de maneiras particulares, e que a classificação produz (bem como reproduz ou subverte) divisões e diferenças, a questão da denominação, entendida como classificação ou categorização, não é sem importância.

A classificação e a categorização influenciam como as pessoas agem e pensam sobre uma dada situação, por isso a preocupação com a questão da classificação é essencial. Termos como 'sem-teto' e 'meninos/as de rua' naturalizam o estado dessas pessoas como condição permanente: não estão sem teto, são sem-teto; não estão na rua, são de rua. Mais recentemente, a situação de rua tem sido representada com freqüência por meio da expressão 'moradores/as de rua'. Ora, há uma contradição evidente nessa classificação: o que determina o fato de alguém ser um/a 'morador/a' é possuir um endereço, um local onde 'mora'. Pois isso é justamente o que (ou melhor, uma das coisas que) um/a 'morador/a de rua' não tem.

Por meio de classificações que legitimam a diferença, a injustiça social é naturalizada, conforme a concepção de Thompson (1995), e deixa de ser questionada como injustiça, passando a ser compreendida como um estado natural de coisas. Por isso opto pelo uso da expressão que me parece captar o problema como uma situação decorrente de um processo sócio-político, e não como um estado definitivo: situação de rua.

A radicalização da precariedade social no Brasil, cujo símbolo máximo é o expressivo e crescente número de pessoas em situação de rua, é resultado de um processo que envolve a miséria no campo e o conseqüente êxodo rural; a exclusão de trabalhadores/as do setor moderno da economia e do trabalho, por conta do modelo de industrialização; a metropolização da pobreza e sua posterior periferização, a chamada 'força centrífuga'; e, por fim, a 'força centrípeta' que determina o retorno da pobreza, agora radicalizada em miséria, aos centros urbanos (SOARES, 2003; BURSZTYN, 2003b). 
No caso da situação de rua em cidades que atraem um sem-número de migrantes pobres, estudos mostram que o êxodo rural tem relevância determinante no crescimento da população nessa situação (BURSZTYN, 2003a). Nesse sentido, Nascimento (2003, p. 57) explica que a pobreza no Brasil "de rural, tornou-se urbana e, em seguida, metropolitana". O movimento da pobreza do campo para as cidades tem sido referido como 'metropolização da pobreza' e, segundo Soares (2003, p. 54), "a concentração da pobreza absoluta nas áreas metropolitanas destaca-se como uma das tendências mais relevantes da distribuição de renda no período recente".

A atração que as grandes cidades passaram a exercer sobre populações pobres deu origem a um outro movimento: a periferização da pobreza "como padrão de localização dos pobres nas metrópoles" (SOARES, 2003, p. 58). Essa 'força centrífuga' que empurrou a pobreza para a periferia acarretou uma notável perda de qualidade de vida entre os/as pobres, pelas longas distâncias a serem percorridas diariamente, pelos elevados gastos com transporte, pelas precárias condições de vida nas favelas, pelos riscos impostos às crianças e jovens.

Mas a precariedade da situação de vida na periferia atua, por sua vez, como uma 'força centrípeta' que atrai a miséria para o centro urbano, espaço que concentra as oportunidades de trabalho informal que se apresentam aos/ às excluídos/as dos setores modernos de produção. Impossibilitados/as de manterem um domicílio no núcleo urbano, essas pessoas têm como alternativa permanecerem continuamente na rua, de onde tiram seu sustento. A pobreza, que tinha sido atraída do campo para a cidade e, então, empurrada para a periferia, "volta ao centro das cidades, desta vez sob a forma de miséria extrema, expressando um 'mal-estar' e constituindo 'ameaça à segurança'” (Bursztyn, 2003b).

Assim, o espaço público passa a constituir o espaço privado de um número cada vez maior de pessoas, que se tornam parte do 'cenário' urbano das principais cidades brasileiras. As classes economicamente privilegiadas já não podem evitar a coexistência espacial com a miséria e, mesmo que prefiram não olhar para aqueles/as que nada têm, não podem deixar de vê-los/as: estão lá. Ao mesmo tempo em que os processos de globalização unem no tempo espaços geograficamente afastados, separam mundos sociais que compartilham o mesmo espaço-tempo. Em outras palavras, Bourdieu (1997, p. 11) argumenta: "há lugares que aproximam pessoas que tudo separa, obrigandoas a coabitarem, seja na ignorância ou na compreensão mútua, seja no conflito, latente ou declarado, com todos os sofrimentos que disso resultem". 
Em algumas cidades, como Brasília, a utopia da inserção no mercado de trabalho deu lugar a um outro atrativo para os movimentos migratórios: o lixo. Perdida a ilusão do trabalho formal, populações radicalmente empobrecidas, no mais das vezes oriundas do Nordeste, passaram a buscar na Capital os recursos provenientes da 'catação' de lixo reciclável. A diferença entre esses/as migrantes e os/as migrantes de outrora é que estes/as migravam na esperança da ascensão social, aqueles/as migram sabendo que encontrarão a pobreza, "vêm em busca do lixo da modernidade" (BUARQUE, 1997, p. 11).

Em verdade, a catação constitui atualmente uma das mais freqüentes formas de subsistência encontradas por pessoas em situação de rua no país: nas grandes cidades é comum verem-se catadores/as com suas rudimentares carroças apinhadas de resíduos da modernidade (ESCOREL, 2003). Muitas vezes as carroças funcionam à tração humana: a posse de animais para a execução desse trabalho caracteriza uma divisão hierárquica entre os/as catadores/as (BURSZTYN; ARAÚJO, 1997). O material reciclável recolhido é vendido a atravessadores/as que cuidam de revendê-lo a indústrias de reciclagem lucrativas, o que constitui a participação desses atores, excluídos de dinâmicas formais da sociedade industrial, em redes de práticas exploratórias.

Em situação ainda mais crítica encontram-se pessoas que não participam, de modo regular, das dinâmicas institucionalizadas da sociedade, pessoas em situação de rua que não executam atividade de catação e sobrevivem de esmolas e da atividade de 'vigiar carros' nas grandes cidades. As políticas públicas não atingem essa parcela da população, que chega a ter o acesso negado a hospitais e postos de saúde, e cujos filhos não podem ser matriculados nas escolas por não terem endereço fixo.

Nesse contexto, os/as radicalmente pobres tornam-se economicamente desnecessários/as, porque a industrialização reduz a necessidade de trabalhadores/ as, sobretudo aqueles/as 'desqualificados/as', 'inempregáveis'; socialmente incômodos/as, "por causa da degradação urbana provocada pela pobreza"; e politicamente ameaçadores/as, uma vez que a precariedade imposta a uma parcela significativa da sociedade acarreta violência (BUARQUE, 2003, p. 32). O tornar-se desnecessário/a, incômodo/a e ameaçador/a muitas vezes implica tornar-se também passível de eliminação, simbólica ou física. De acordo com Nascimento (2003, p. 62), "estes grupos sociais passam a 'não ter direito a ter direitos'. Sem serem reconhecidos como semelhantes, a tendência é expulsálos da órbita da humanidade. Passam, assim, a ser objeto de extermínio". É o que temos presenciado, estarrecidos/as, nas freqüentes chacinas praticadas por 
grupos de extermínio especializados nessa atividade. Não menos estarrecedora é a eliminação simbólica dessas pessoas, por meio da negação de sua identidade como seres humanos.

A negação da identidade como semelhante está no cerne do conceito de apartação. Buarque (2001, p. 34) esclarece que "o centro do conceito de apartação está em que o desenvolvimento brasileiro não provoca apenas desigualdade social, mas uma separação entre grupos sociais". Nesse sentido, o autor propõe um continuum entre os conceitos de desigualdade, diferença e dessemelhança. Em um caso de desigualdade, as classes sociais, embora desiguais, convivem em uma relação de necessidade mútua, e todas têm acesso aos bens essenciais como alimentação, saúde, educação. O que as torna desiguais é o acesso ao consumo de bens e serviços supérfluos. Nesse sentido, a desigualdade social constitui a distinção entre pessoas do mesmo lado da fronteira social. A diferença, por outro lado, refere-se à distinção entre os dois lados dessa fronteira. O que distingue a dessemelhança da diferença é a perda do "sentimento de semelhança", do juízo ético que nos faz sentir, todos/as, membros de uma mesma espécie de indivíduos.

Acredito que a naturalização da injustiça social caminha lado a lado com a legitimação da globalização como 'fenômeno' inescapável: tanto uma como outra são percebidas como a-históricas, independentes de ação política humana. Simplesmente uns tem sorte e outros não, ou, o que é pior, uns são competentes e outros não. Isso se relaciona à falta de mobilização social dos/as classes abastadas e de abordagem prioritária do problema pelo poder público - se não é uma injustiça, não há porque se indignar. Segundo Dejours (2003, p. 19), "nem todos partilham hoje do ponto de vista segundo o qual as vítimas do desemprego, da pobreza e da exclusão social seriam também vítimas de uma injustiça”.

O sofrimento alheio somente suscita sentimento de revolta quando é percebido como consequiência de injustiça, o que não tem acontecido com relação à precariedade social. Sem dúvida, estsa percepção das coisas não é construção individual: decorre de construçóes sócio-discursivas, da naturalização de processos sociais como fenômenos e da legitimação de determinadas posições como sendo justas. Por isso o enfrentamento das situações de precariedade tem de ser necessariamente baseado na ética, em termos de mudança de prioridades e de estratégia política (BUARQUE, 1999). 


\section{O problema: o grupo de pessoas em situação de rua, 0 condomínio e a circular}

O texto a ser analisado é o "relatório sucinto" de uma reunião, distribuído aos/às condôminos/as de um edifício residencial como circular de condomínio. O edifício localiza-se na Asa Sul do Plano Piloto de Brasília, bairro de classe média. O endereço do edifício, bem como os nomes dos/as envolvidos/as na reunião foram omitidos, a fim de garantir seu anonimato (ver ANEXO A).

A reunião de que a circular trata foi referente à prolongada permanência de um grupo de pessoas em situação de rua nas proximidades do edifício residencial e de estabelecimentos do comércio local. Essa reunião foi convocada pelo proprietário de um restaurante e contou com a participação de síndicos de prédios da quadra e representantes do Governo do Distrito Federal.

A imagem de satélite copiada a seguir, obtida com o recurso do Google Earth, mostra como se localizam o prédio residencial, o local ocupado à época pelo grupo de pessoas em situação de rua para abrigo e trabalho, e o restaurante cujo dono convocou a reunião. A imagem é copiada aqui para esclarecer aspectos da narrativa da história que deu origem à circular a ser analisada, o que considero relevante para a delimitação do problema.

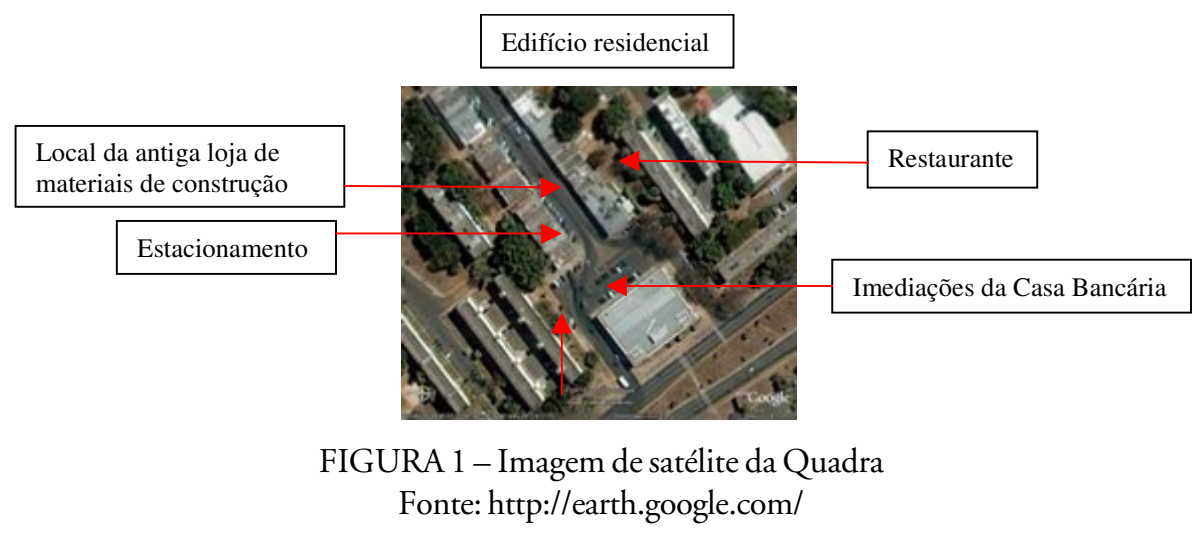

O grupo de pessoas em situação de rua estabeleceu-se na região há cerca de três anos. À época, uma loja de materiais de construção na esquina do comércio da quadra fechou, deixando disponível uma área coberta de cerca de $40 \mathrm{~m}^{2}$. O grupo já freqüentava a área comercial da quadra que, por ser uma tradicional zona boêmia no bairro, atraía, todas as noites, muitas pessoas que estacionavam seus carros na proximidade da esquina do comércio. O grupo 
tinha como trabalho 'vigiar os carros' das pessoas que vinham se divertir nos bares. Depois de 'vigiar os carros', eles se retiravam para locais próximos onde mantinham seus barracos de lona. Com o encerramento das atividades da loja de materiais de construção, o grupo passou a ocupar o espaço disponibilizado por meses de inutilização comercial do ponto, que fica bem em frente ao prédio residencial cujo síndico escreveu a circular de condomínio que me serve de objeto de análise.

O estabelecimento do grupo naquele local causava desconforto aos/às moradores/as do prédio, pois não eram raras as situaçóes em que o grupo consumia bebidas alcoólicas ou se envolvia em situações de violência entre membros do próprio grupo ou com a polícia, que vinha chamada por moradores/as da região e fazia uso da já institucionalizada violência de Estado. Proprietários/as de estabelecimentos comerciais da quadra também se sentiam financeiramente prejudicados/as.

Foi nesse contexto que se realizou a reunião referida na circular de condomínio. A situação estendeu-se por muitos meses, até que o ponto comercial fosse ocupado por outro restaurante, este, ironicamente, um restaurante de luxo. Com a expulsão da área que se constituíra em seu abrigo por meses, o grupo viu-se obrigado a permanecer nas imediaçóes da casa bancária que ocupa grande área da entre-quadra daquele local, visto que seu trabalho precário está atrelado ao estacionamento ali localizado. À noite, o grupo se retira para abrigar-se sob árvores e barracos de lona; estes são periodicamente destruídos ou queimados por funcionários de órgãos públicos. Essa é a situação que perdura até hoje.

\section{Análise da circular de condomínio}

Nesta seção, procedo à análise da circular de condomínio com base nas seguintes categorias lingüístico-discursivas: estrutura genérica, modalidade, intertextualidade, pressuposição e avaliação. A seguir, farei uma breve explanação sobre cada uma dessas categorias para depois, em apresentar uma análise discursiva crítica do texto.

\section{As categorias para análise lingüístico-discursiva}

Gêneros constituem "o aspecto especificamente discursivo de maneiras de ação e interação no decorrer de eventos sociais" (FAIRCLOUGH, 2003, p. 65). Quando se analisa um texto em termos de gênero, o objetivo é 
examinar como o texto figura na (inter)ação social e como contribui para ela em eventos sociais concretos. Gêneros discursivos variam em relação aos níveis de abstração. Fairclough (2003) distingue os pré-gêneros e os gêneros situados. Pré-gêneros são categorias mais abstratas, que transcendem redes particulares de práticas sociais e que 'participam' na composição de diversos gêneros situados. Narrativa, argumentação, descrição e conversação são pré-gêneros no sentido de que são 'potenciais' abstratos que podem ser alçados na composição de diversos tipos de texto. Gêneros situados, por outro lado, são categorias concretas, utilizadas para definir gêneros que são específicos de uma rede de prática particular, como a circular de condomínio. Um gênero situado é "um tipo de linguagem usado na performance de uma prática social particular" (CHOULIARAKI; FAIRCLOUGH, 1999, p. 56), por isso a categoria de gênero discursivo relaciona-se ao significado acional de textos, a seu funcionamento no estabelecimento de relaçóes sociais particulares, textualmente mediadas.

Bakhtin (2002), um dos precursores da análise de discurso (FAIRCLOUGH, 2001; ver também RESENDE; RAMALHO, 2006), enfatizou a importância da linguagem para as relaçôes sociais, teorizando sobre sua dialogicidade. Para ele, textos são dialógicos em dois sentidos: primeiro, mesmo textos aparentemente monológicos, como os textos escritos, participam de uma cadeia dialógica, no sentido de que respondem a outros textos e antecipam respostas; segundo, o discurso é internamente dialógico porque é polifônico, todo texto articula diversas vozes.

Em linhas gerais, a intertextualidade é a combinação da voz de quem pronuncia um enunciado com outras vozes que lhe são articuladas. Para relatar um discurso, pode-se não apenas citar em discurso direto, mas também parafrasear, resumir, ecoar, em discurso indireto. $\mathrm{O}$ discurso relatado atribui o dito a seu autor, mas a incorporação de elementos de outros textos também pode ser feita sem atribuição explícita. Assim, a intertextualidade cobre uma gama diversa de possibilidades.

A intertextualidade conecta um texto a outros textos, nem sempre claramente distinguíveis, e a pressuposição também o faz. Fairclough (2003, p. 40) define a pressuposição como "o que não é dito, mas tomado como dado". O que aproxima a pressuposição da intertextualidade é que aquela também relaciona o texto ao "que foi dito ou escrito ou pensado em outro lugar”, mas esse 'outro lugar' é deixado vago. O que afasta a pressuposição da intertextualidade é, sobretudo, que a primeira constitui uma abertura para a diferença, trazendo outras vozes ao texto, e a segunda constitui um fechamento, uma vez que presume um conhecimento geral, tomado como dado. 
A orientação para a diferença é uma questão da dinâmica da interação discursiva, em seu aspecto acional. A relação dessa orientação com o aspecto representacional é que representaçôes externas ao texto (interdiscursivas) variam na proporção em que são afirmadas ou presumidas; e a relação entre o balanço asserção/presunção e a hegemonia é que "uma medida do sucesso da universalização de uma representação do mundo é o quanto figura como assunção (como dado) em uma variedade de textos" (FAIRCLOUGH, 2003, p. 46). Nesse sentido, Fairclough sugere um continuum em que a opção mais dialógica é a atribuição do dito à voz que diz, a citação; em seguida, tem-se a asserção modalizada e a asserção não-modalizada; por fim, a opção menos dialógica é a pressuposição.

Por meio de estruturas de pressuposição é possível construir avaliações implícitas em textos. São as chamadas assunções valorativas. São os casos em que a avaliação não é engatilhada por marcadores relativamente transparentes de avaliação, em que os valores estão mais profundamente inseridos nos textos. A construção de significado depende não só do que está explícito em um texto, mas também do que está implícito - o que está presumido. O que está 'dito' em um texto sempre se baseia em presunções 'não ditas'; então, parte do trabalho de se analisar textos é tentar identificar o que está presumido. Conforme Fairclough (2003, p. 58) indica, significados presumidos são de particular relevância ideológica - "pode-se dizer que relações de poder são mais eficientemente sustentadas por significados tidos, amplamente, como tácitos".

A categoria da modalidade também se relaciona à avaliação em textos, no sentido de que, segundo Halliday (1985, p. 75), a modalidade é "o julgamento do falante sobre as probabilidades ou obrigatoriedades envolvidas no que diz". Para esse autor, a modalidade associa-se a "um traço semântico essencial": a polaridade. A polaridade é a escolha entre positivo e negativo, como na oposição 'é/ não é'; e a modalidade, para Halliday, são as possibilidades intermediárias entre sim e não, ou seja, os tipos de indeterminação situados entre os pólos.

Em proposiçôes (trocas de informação), o significado dos pólos positivo e negativo é afirmar e negar ('isso é assim'/ 'isso não é assim'), sendo que há dois tipos de possibilidades intermediárias: os graus de probabilidade e os graus de freqüência. Os graus de probabilidade variam, por exemplo, entre 'possivelmente', 'provavelmente', 'certamente'; ao passo que os graus de freqüência variam, por exemplo, entre 'às vezes', 'normalmente', 'sempre' (HALLIDAY, 1985, p. 86). 
Em propostas (trocas de "bens e serviços"), o significado dos pólos positivo e negativo envolve prescrever e proscrever, respectivamente ('faça isso') 'não faça isso'), e há também dois tipos de possibilidades intermediárias, nesse caso relacionados à função do discurso. Em uma ordem, os pontos intermediários entre a prescrição e a proscrição representam graus de obrigatoriedade, variando como no continuum permitido/ esperado/ obrigado. Em uma oferta, os pontos intermediários representam graus de inclinação, como em desejoso de/ ansioso por/ determinado a.

Em seu modelo para análise textual em ADC, Fairclough (2003) retoma a teoria de modalidade de Halliday, afirmando que "a questão da modalidade pode ser vista como a questão de quanto as pessoas se comprometem quando fazem afirmaçōes, perguntas, demandas ou ofertas". Afirmações e perguntas referem-se à troca de conhecimento (a troca de informação de Halliday); demandas e ofertas referem-se à troca de atividade (a troca de bens e serviços de Halliday), sendo que todas essas funçôes discursivas relacionam-se à modalidade. Em trocas de conhecimento, a modalidade é epistêmica, referese ao comprometimento com a 'verdade'; em trocas de atividade, a modalidade é deôntica, refere-se ao comprometimento com a obrigatoriedade/ necessidade.

Embora Halliday (1985, p. 86) defina como modalidade "os graus intermediários entre os pólos positivo e negativo", de modo que as proposiçōes polares (asserção e negação absolutas) ficam fora do estudo da modalidade, Fairclough assume uma categoria ampla de modalidade, que inclui os pólos. Fairclough acrescenta também uma distinção entre modalidade objetiva e modalidade subjetiva. $\mathrm{Na}$ modalidade objetiva, a base subjetiva do julgamento está implícita: não fica claro qual o ponto de vista privilegiado na representação, se "o falante projeta seu ponto de vista como universal ou age como veículo para o ponto de vista de um outro indivíduo ou grupo" (FAIRCLOUGH, 2001, p. 200). Na modalidade subjetiva, a base subjetiva para o grau de afinidade com a proposição é explicitada, deixando claro que a afinidade expressa é do próprio falante.

Quando em um texto se combinam características como fechamento para a diferença, avaliações com base em estruturas pressupostas, alta densidade de modalidades categóricas, o efeito social das construções lingüísticas pode ser a vinculação a uma lógica de aparências e a universalização de perspectivas particulares acerca de questões sociais (RESENDE, 2005). Por isso as categorias lingüísticas de análise são importantes em ADC: por meio de análises discursivas lingüisticamente orientadas é possível relacionar textos a seus 
(inter)contextos e às conjunturas sociais mais amplas, fazendo da análise lingüística uma ferramenta para a crítica social.

\section{Análise discursiva crítica da circular de condomínio}

O texto a ser analisado configura-se no gênero situado 'circular de condomínio', cujo propósito é estabelecer comunicação entre o/a síndico/a de um condomínio residencial ou comercial e os condôminos, a respeito de temas relevantes para o funcionamento da comunidade, como pagamentos, pendências ou problemas envolvendo o conjunto da comunidade. No caso do texto em análise, trata-se de circular de condomínio residencial, texto produzido individualmente pelo síndico e distribuído aos condôminos por meio de cópias impressas que foram deixadas nas caixas de correio das unidades domiciliares.

Em termos de gênero, a amostra discursiva é relativamente inovadora - circulares de condomínio geralmente versam sobre debates internos ao condomínio, sobre reuniões realizadas entre condôminos ou problemas específicos ao funcionamento do condomínio. Essa circular, por outro lado, traz relatório de um debate envolvendo agentes externos à comunidade de condôminos, em reunião à qual estes não foram convidados a comparecer.

No tangente à estrutura genérica, a circular recorre aos pré-gêneros narração e argumentação. Vejamos os excertos destacados no exemplo (1).

(1) Na reunião com Autoridades do Governo do Distrito Federal, convocada pelo proprietário do Restaurante XXXXX, estiveram presentes conosco os senhores XXXXX, XXXXX e a Sra. XXXXX [...]

Gostaria também de colocá-los a par, uma informação passada na reunião $[. .$.

Nós também somos responsáveis, como foi dito pelo representante da Segurança Pública presente na reunião, da permanência deles, onde estão.

Nos trechos narrativos, identificados pelo uso de verbos no passado, tempo nuclear do mundo narrado, a referência à reunião realizada "com Autoridades do Governo do Distrito Federal", assim como a seus participantes, é utilizada como argumento de autoridade para legitimar as posturas 
defendidas no texto. As informações trazidas pelas autoridades governamentais assumem status de verdade indiscutível, dada a apresentação da fonte institucional.

A maior parte do texto, entretanto, recorre ao pré-gênero argumentação. Nesses casos, a argumentação assume a aparência de trocas de informação, uma vez que a base subjetiva dos julgamentos não é explicitada. Em todo o texto as modalidades são categóricas. No único caso de troca de atividade, a modalidade deôntica é categórica pela dupla negação e pelo uso do verbo no imperativo ("não dê nada a eles"); no restante do texto, as modalidades são epistêmicas categóricas e objetivas. Essa estrutura de modalização tem o efeito de conferir caráter universal a certas representaçóes particulares, o que é fundamental para o funcionamento do texto. Embora fique evidente que o propósito principal do texto é a troca de atividade - ou seja, o interdito a relações de solidariedade entre os condôminos e o grupo de pessoas em situação de rua -, o predomínio das aparentes trocas de informação, fortalecidas pelo argumento de autoridade e pelas modalidades objetivas, ao mesmo tempo, mitiga esse propósito de interdição e intensifica o poder dos argumentos utilizados.

O texto estabelece relações intertextuais pela seleção de vozes de "Autoridades do Governo" e do "representante da segurança pública", por meio de representação indireta do que foi dito na reunião. Trata-se de uma representação mais voltada ao significado ideacional do que às palavras atualizadas na reunião - o discurso representado como sendo o discurso das autoridades é tomado como dado, assumido com alta afinidade pelo autor da circular e utilizado como argumento autoritativo na legitimação de uma posição particular.

Embora a expressão "moradores de rua" só apareça no texto uma única vez, fica claro ser esse o tema da circular. Ainda, embora a referência a "moradores de rua" seja feita como referência genérica, no primeiro parágrafo ("as causas que levam os moradores de rua a permanecerem mais tempo em um só lugar"), o restante do texto esclarece tratar-se de um grupo particular, mas essa especificação não é feita de modo explícito, e sim tomada como dado. $\mathrm{O}$ grupo de pessoas em situação de rua é referido por meio da pronominalização ("eles", "deles"). Essa representação pronominal do grupo sugere a divisão antagônica nós X eles, o que indica a exclusão social do grupo e o apagamento de seu problema: o problema que se coloca não é a situação de rua, mas a "permanência deles perto do nosso prédio". 
A avaliação do grupo de pessoas em situação de rua é feita no texto por meio de estruturas de pressuposição. Vejamos o excerto destacado em (2), os grifos são originais.

(2) [...] as causas que levam os moradores de rua a permanecerem mais tempo em um só lugar é a facilidade de obterem as coisas básicas necessárias como: comida, roupas, calçados e dinheiro, sendo este último transformado nas drogas que utilizam.

Gostaria também de colocá-los a par, uma informação passada na reunião, de que existem duas ou três pessoas recentemente libertadas da penitenciária e que estão ainda na condicional, entre eles.

O excerto em destaque ilustra estruturas de pressuposição que formulam uma avaliação das pessoas do grupo como oportunistas e perigosas. São classificadas como oportunistas no primeiro parágrafo do excerto, em que se define implicitamente a situação de rua como sendo 'fácil'. De acordo com o pressuposto necessário para a interpretação de "a facilidade de obterem as coisas básicas necessárias”, a situação de rua é vista como uma opção, apagando o desemprego crônico como problema social. Isso se coaduna com o discurso neoliberal, da sociodicéia da competência, segundo o qual as pessoas seriam individualmente responsáveis por seu sucesso ou por seu fracasso (BOURDIEU, 1997). O segundo parágrafo do excerto opera uma avaliação das pessoas do grupo em situação de rua como perigosas, por meio da "informação passada na reunião" de que haveria ex-presidiários/as no grupo. Ao mesmo tempo em que sugere sua periculosidade, o autor da circular reforça o preconceito contra pessoas egressas do sistema prisional e o estigma que pesa sobre elas. Isso fica patente no trecho que segue esse excerto na circular, como se vê no exemplo (3), grifo no original:

(3) Por isso, gostaria de enfatizar novamente, não dê nada a eles.

Por meio do estabelecimento de uma relação causal entre "existem duas ou três pessoas recentemente libertadas da penitenciária" e "não dê nada a eles", explicitamente marcada em "por isso", o autor deixa claro que a exclusão de ex-presidiários/as não seria merecedora de indignação e que não se trata de pessoas dignas de solidariedade. De acordo com esse raciocínio, sua condição como infratores/as da Lei justificaria sua apartação da sociedade, que faria bem 
em lhes virar as costas e em não enxergar sua exclusão. $\mathrm{O}$ trecho seguinte da circular completa esse sentido, numa espécie de racionalização que, pode-se imaginar, visa tranqüilizar a consciência por essa miopia social. O trecho está destacado no exemplo (4), grifo original.

(4) Não é falta de humanidade, é simplesmente para dificultar a permanência deles perto do nosso prédio.

Nesse excerto, o autor procura apresentar uma justificativa para a demanda que configura a troca de atividade determinante de seu texto - o interdito a relações entre condôminos e o grupo de pessoas em situação de rua. De acordo com essa racionalização, o conforto pessoal/ comunitário justificaria uma atitude que poderia ser classificada como "falta de humanidade", justificando também a apartação social do grupo. Uma vez que a causa da permanência do grupo "em um só lugar" é definida como sendo "a facilidade de obterem as coisas básicas necessárias", a racionalização apresentada indica como solução "dificultar a permanência deles perto do nosso prédio". Os sentidos de 'facilidade' e 'dificultar' relacionam-se por oposição.

Há aqui uma dissimulação do problema. Em vez de se reconhecer a estrutura que desagrega parcelas da população, impedindo a coesão social, como sendo o problema a ser enfrentado, focaliza-se como problema a permanência do grupo em um local que causa incômodo a parcelas da população incluídas sócio-economicamente. A dissimulação é reforçada pelo uso do advérbio "simplesmente", cujo sentido ofusca a gravidade da questão social. Além disso, quando se formula como sendo o problema a ser enfrentado a permanência do grupo "em um só lugar" reifica-se sua condenação ao nomadismo: não se configura como um problema sua situação de rua, mas sua fixação prolongada em um mesmo local, o que obriga os/as residentes na região ao convívio com suas misérias diárias.

Esse convívio prolongado muitas vezes faz com que algumas pessoas tomem conhecimento de histórias de desagregação, conheçam pequenas partes das condições que levaram membros do grupo à situação de rua, desenvolvam laços de solidariedade, procurem meios de colaborar para sua subsistência, doando "coisas básicas necessárias", ou, em casos menos freqüentes, para a melhora de sua condição de trabalho, ajudando a comprar carroças para a coleta de materiais recicláveis, por exemplo, ou ajudando financeiramente para seu regresso a sua região de origem, uma vez que muitas das pessoas nessa situação 
em Brasília são migrantes que vêm à cidade 'tentar a sorte’ e logo percebem que 'a sorte' não mora ali, mas não encontram as condiçôes financeiras para o regresso.

Mas a verdade é que a maior parte das pessoas apenas doa "coisas básicas necessárias", evitando se envolver com as histórias pessoais de desagregação. É o que se nota no último parágrafo, quando o autor retoma o tom narrativo para relatar um fato:

(5) Ontem mesmo presenciamos pessoas jogarem sacos de comida para alguns deles embaixo do prédio.

Esse flagrante ilustra um tipo especial de segregação, típico de sociedades contemporâneas: mesmo quando se sensibilizam com a miséria e, às vezes até por motivos religiosos, sentem-se penalizadas com a fome, as pessoas evitam um maior envolvimento, evitam o estabelecimento de relações humanas com esses seres humanos de categoria diferenciada pela apartação. Mesmo essa atitude de 'jogar sacos de comida' pela janela, para serem recolhidos por sujeitos separados por metros de distância física e quilômetros de distância social, é interditado pelo síndico, sob a justificativa expressa no exemplo (6):

(6) Nós também somos responsáveis, como foi dito pelo representante da Segurança Pública, da permanência deles, onde estão.

Não se trata de uma responsabilização cidadã pela insalubre condição de vida a que estão submetidas essas pessoas, uma responsabilização que pediria luta política por sua inclusão, exigência de políticas públicas para essas populações que, por não terem endereço e por muitas vezes não terem nem mesmo documentos de identificação, não são incluídas nas estatísticas oficiais nem nas políticas públicas de transferência de renda. Trata-se, ao contrário, de uma responsabilização "simplesmente" por sua fixação incômoda na vizinhança, pela proximidade desconfortável do sofrimento alheio. A representação da voz do "representante da Segurança Pública" encerra um apagamento das responsabilidades do Estado, que é reificado pelo síndico em sua circular.

Assim, por meio de sua vinculação a uma lógica de aparências, o texto opera um apagamento do grave problema social que é a situação de rua e uma dissimulação desse problema pela ênfase no conforto individual/ comunitário. A circular reifica a apartação dessa parcela da população e preconceitos enraizados na sociedade, filiando-se ao discurso neoliberal segundo o qual cada 
um deve carregar a culpa de sua 'inaptidão' social, de sua desqualificação profissional, de sua inempregabilidade crônica. Justificam-se a demissão do Estado e a ausência de políticas públicas para essas pessoas por meio de sua avaliação como oportunistas, e justifica-se a miopia social, a invisibilidade dessas pessoas, por meio de sua avaliação como perigosas. $\mathrm{O}$ texto reitera um deslocamento do problema social que apaga suas conseqüências sobre as próprias populações em situação de rua quando focaliza apenas seus efeitos sobre grupos sócio-economicamente incluídos. Não se questiona o fato de seres humanos terem negados seus direitos sociais básicos, assegurados na Declaração Universal dos Direitos Humanos e na Constituição Brasileira, embora nunca conquistados de fato.

\section{Considerações finais}

Alguns efeitos ideológicos do texto são a justificativa da apartação por meio da avaliação negativa do grupo de pessoas em situação de rua; a redução do problema ao conforto e bem-estar dos condôminos, que deveriam se sentir incomodados/as e ameaçados/as pela presença do grupo; a legitimação da negação de direitos sociais básicos a uma parcela da população; o apagamento de responsabilidades do Estado e da sociedade em relação a essa situação.

Evidentemente esses sentidos não são criados nessa circular de condomínio. São aqui recriados, ressignificados, recolocados em prática. Isso sugere o poder da repetibilidade de discursos na manutenção de estruturas de poder e dominação, visto que a avaliação negativa de grupos apartados e a desresponsabilização do Estado são muitas vezes repetidas em variados tipos de texto, tornando-se parte dos pressupostos sobre os quais novos textos são construídos. Essa circular de condomínio é um exemplo disso. Por outro lado, a ausência de respostas a esse texto é um indício de leituras domesticadas, filiadas a esses mesmos discursos, afinadas com a significação expressa ou, pelo menos, acomodadas à hegemonia desses discursos.

Nesse contexto, análises discursivas críticas de textos envolvendo pessoas em situação de pobreza extrema, tanto de textos produzidos por elas, em pesquisa etnográfica, quanto de textos sobre elas, veiculados em diversos meios, podem representar um modo de deslocamento desses discursos legitimados, de desvelamento de dissimulações ideológicas, e, assim, configurar-se ferramenta de luta política contra situações de opressão e miséria. 


\section{Referências}

BAKHTIN, M. Marxismo e filosofia da linguagem. São Paulo: Hucitec, 2002 [1929].

BOURDIEU, P. (Org.) A miséria do mundo. Petrópolis: Vozes, 1997.

. Contrafogos: táticas para enfrentar a invasão neoliberal. Rio de Janeiro: Jorge Zahar Editor, 1998.

BUARQUE, C. A diáspora da modernidade. In: BURSZTYN, M; ARAÚJO, C.H. Da utopia à exclusão: vivendo nas ruas em Brasília. Rio de Janeiro: Garamond; Brasília: Codeplan, 1997. p. 9-12. Prefácio.

. A segunda abolição: um manifesto-proposta para a erradicação da pobreza no Brasil. São Paulo: Paz e Terra, 1999.

- Admirável mundo atual: dicionário pessoal dos horrores e esperanças do mundo globalizado. São Paulo: Geração Editorial, 2001. 2003.

O que é apartação: o apartheid social no Brasil. São Paulo: Brasiliense,

BURSZTYN, M. (Org.). No meio da rua: nômades, excluídos e viradores. Rio de Janeiro: Garamond, 2003a.

Da pobreza à miséria, da miséria à exclusão: o caso das populações de rua. In: BURSZTYN, M. (Org.). No meio da rua: nômades, excluídos e viradores. Rio de Janeiro: Garamond, 2003b. p. 27-55.

; ARAÚJO, C.H. Da utopia à exclusão: vivendo nas ruas em Brasília. Rio de Janeiro: Garamond; Brasília: Codeplan, 1997.

CEVASCO, M.E. In: JAMESON, F. A cultura do dinheiro: ensaios sobre a globalização. Petrópolis: Vozes, 2001. p. 7-16. Prefácio.

CHOULIARAKI, L.; FAIRCLOUGH, N. Discourse in late modernity: rethinking critical discourse analysis. Edinburgh: Edinburgh University Press, 1999.

DEJOURS, C. A banalização da injustiça social. Rio de Janeiro: FGV Editora, 2003.

ESCOREL, S. Vivendo de teimosos: moradores de rua da cidade do Rio de Janeiro. In: BURSZTYN, M. (Org.). No meio da rua: nômades, excluídos e viradores. Rio de Janeiro: Garamond, 2003. p. 139-171.

FAIRCLOUGH, N. Discurso e mudança social. Brasília: Editora Universidade de Brasília, 2001.

. Analyzing discourse: textual analysis for social research. London:

Routledge, 2003. 
FAIRCLOUGH, N. Language and globalization. London: Routledge, 2006.

HALLIDAY, M.A.K. An introduction to functional grammar. London: Hodder Arnold, 1985.

NASCIMENTO, E.P. Dos excluídos necessários aos excluídos desnecessários. In: BURSZTYN, M. (Org.). No meio da rua: nômades, excluídos e viradores. Rio de Janeiro: Garamond, 2003.

RESENDE, V. M. Literatura de cordel no contexto do novo capitalismo: o discurso sobre a infância nas ruas. 2005. Dissertação (Mestrado em Lingüística) Instituto de Letras, Universidade de Brasília, Brasília.

RESENDE, V. M.; V. RAMALHO. Análise de Discurso-Crítica. São Paulo: Contexto, 2006.

SOARES, L.T. O desastre social. Rio de Janeiro: Record, 2003.

THOMPSON, John B. Ideologia e cultura moderna. Petrópolis: Vozes, 1995.

WODAK, R. De qué trata el análisis crítico del discurso (ACD). Resumen de su historia, sus conceptos fundamentales y sus desarrollos. In: WODAK, R.; MEYER, M. (Org.). Métodos de Análisis Crítico del Discurso. Barcelona: Gedisa, 2003. p. 17-34. 


\section{ANEXO A}

\section{A circular de condomínio (grifos no original)}

\section{RELATÓRIO SUCINTO DA REUNIÃO}

$\mathrm{Na}$ reunião com Autoridades do Governo do Distrito Federal, convocada pelo proprietário do Restaurante XXXXX, estiveram presentes conosco os senhores XXXXX, XXXXX e a Sra. XXXXX, onde ouvimos que as causas que levam os moradores de rua a permanecerem mais tempo em um só lugar é a facilidade de obterem as coisas básicas necessárias como: comida, roupas, calçados e dinheiro, sendo este último transformado nas drogas que utilizam.

Gostaria também de colocá-los a par, uma informação passada na reunião, de que existem duas ou três pessoas recentemente libertadas da penitenciária e que estão ainda na condicional, entre eles. Por isso, gostaria de enfatizar novamente, não dê nada a eles. Não é falta de humanidade, é simplesmente para dificultar a permanência deles perto do nosso prédio.

Ontem mesmo presenciamos pessoas jogarem sacos de comida para alguns deles embaixo do prédio. Nós também somos responsáveis, como foi dito pelo representante da Segurança Pública presente na reunião, da permanência deles, onde estão.

Esperamos ter-nos entendido e agradecemos a ajuda.

XXXXX - Síndico 


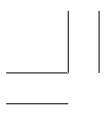

